\title{
2006 Best Student Paper Awards
}

\section{Astronomy, Mathematics, and Physics}

Best Student Paper:

Using Neural Networks to Model Electron-Nucleon Cross-Sections.

John A. Telfeyan, Department Physics and Astronomy, James Madison University

Honorable Mention:

Determination of Relative Concentrations of Hydrogen Isotopes.

Laurence A. Lewis, Department of Physics and Astronomy, James Madison University

\section{Agriculture, Forestry, and Aquaculture}

Best Student Paper:

Effects of Central and Peripheral Xenin Administration on Appetite, Feed Passage Rate, and Brain Chemistry in 4-Day Post Hatch Chicks.

Wint Nandar, Department of Biology, Radford University.

Honorable Mention:

Effect of Intracerebroventricular Administration of Neurotensin on Feed Intake in Goldfish.

Marissa L. Smith, Department of Biology, Radford University.

\section{Biology with Microbiology and Molecular Biology}

Best Student Paper:

The TVN0703 Protein from Thermoplasma volcanium, a Probable Archaeal Metaldependent Serine/threonine Protein Phosphatase.

AbdulShakur H. Abdullah, Department of Biochemistry, Virginia Tech.

Best Student Paper:

Mapping of BGAF-binding Regions on the Maize b-glucosidase Isozyme Glu1.

H. Y. Yu, Department of Biological Sciences, Virginia Tech.

Best Student Paper:

Boundary Effects upon Population Distribution: Theoretical Model and Case Study.

Steven Hand, Department of Natural Sciences, Shenandoah University.

Honorable Mention:

A Study of the Proteome of the Apical Segment Membranes of Guinea Pig Spermatozoa.

Sara S. Hirsch, Department of Biology, Randolph-Macon College. 


\section{Biomedical and General Engineering}

Best Student Paper:

Changes in Balance with Low Back Fatigue.

Bradley S. Davidson, School of Biomedical Engineering and Sciences, Virginia Tech.

Honorable Mention:

Mechanics and Structure of Vestibular Hair Bundles.

Corrie E. Spoon, School of Biomedical Engineering and Sciences, Virginia Tech.

Honorable Mention:

An Affordable Haptic Display for the Interpretation of 2-D Graphics by Individuals Who Are Blind or Have Visual Impairments.

David S. Burch, Department of Biomedical Engineering, Virginia Commonwealth University

\section{Botany}

Best Student Paper:

Phylogeny of the Genus Arachis.

Sheena A. Friend, Department of Biological Sciences, Virginia Tech.

Honorable Mention:

Phylogenetic Analysis of Phalaenopsis (Orchidaceae) Using Chloroplast DNA Sequences - an Update.

Yelena Lazdun, Department of Biological Sciences, University of Mary Washington.

Honorable Mention:

Sorocarp Formation in Polysphondylium: Altruism or Social Strife?

Carla D. Glass, Department of Natural Sciences, UVA-Wise.

\section{Chemistry}

Best Student Paper:

Preparation and Characterization of Hydrogenated Trimetallic Nitride Endohedrdal Metallofullerenes.

Wujunn Fu, Department of Chemistry, Virginia Tech.

Honorable Mention:

Predicting the Singlet Oxygen Quantum Yield of Humic Substances from Spectroscopic Properties.

Renee M. Dalrymple, Department of Chemistry, University of Mary Washington.

Honorable Mention:

Analytical Strategies Related to Accuracy and Precision in an ICP-MS Trace Analysis Problem in Instrumental Analysis.

Ashley M. Lakner, Department of Chemistry, James Madison University. 
Environmental Sciences

Best Graduate Student Paper:

Evaluation of Fall Soil Sampling for Predicting Spring Infestation of Secondary Soil

Pests in Corn.

Timothy A. Jordan, Department of Entomology, Virginia Tech.

Best Undergraduate Student Paper:

Comparative Analysis of the Impact of Development on the Health of Two Stream Tributaries of the Rappahannock River.

Justin Park, Department of Environmental Sciences \& Geology, University of Mary Washington.

Honorable Mention:

An Assessment of the Water Quality of Crooked Run in Frederick, Clarke and Warren Counties, VA, Based on their Fish Populations.

Lyla H. Gray, Environmental Studies Program, Shenandoah University.

Best Undergraduate Student Poster:

Monitoring the Progress of a Wetland Mitigation Project for Cental Park in Fredericksburg, Virginia.

Michelle L. Arthur, Department of Environmental Sciences \& Geology, University of Mary Washington.

\section{Medical Sciences}

Best Student Paper:

The Genetic Analysis of Ethanol-induced Anxiolysis in BXD Recombinant Inbred Mice.

Alexander H. Putman, Department of Pharmacology and Toxicology, Virginia Commonwealth University.

Honorable Mention:

Biodevelopment of Osteocytes from Mesenchymal Stem Cells Derived from Umbilical Cord Blood and Adult Bone Marrow.

Andrew P. Pacitti, Department of Physiology, Virginia Commonwealth University.

Honorable Mention:

FGF23 Regulation of 1-alpha-Hydroxylase in the Proximal Kidney Tubule.

Megan Forster, Department of Physiology, Virginia Commonwealth University.

\section{Natural History and Biodiversity}

Best Student Paper:

Effect of size and temperature on oxygen consumption in the hissing cockroach (Gromphadorhina portentosa).

Jeff W. Streicher, Department of Environmental Science and Policy, George Mason University. 
Honorable Mention:

A Comparative Study of the Harvestmen of the Family Manaosbiidae (Opiliones, Laniatores) from Trinidad, W. I.

Daniel Proud, VA Wesleyan College.

Honorable Mention:

Experimental Effects of Forest Regeneration Methods on Salamander Populations up to 11-years Post-treatment.

Jessica A. Homyack, Department of Fisheries and Wildlife Sciences, VA Tech.

\section{Psychology}

Best Graduate Student Paper:

The Effects of Relative System Reliability and Prioritization on Alarm Reaction Patterns.

Elizabeth T. Newlin, Department of Psychology, Old Dominion University.

Best Undergraduate Student Paper:

Improving Memory in the Elderly Via Positive Feedback.

Kathryn Van Veen, Department of Psychology, Washington and Lee University.

\section{Statistics}

Best Student Paper:

A Semi-Parametric Approach to Robust Parametric Design.

Stephanie M. Pickle, Department of Statistics, Virginia Tech.

Honorable Mention:

Ranges of Measures of Association for Familial Binary Variables.

Yihao Deng, Department of Mathematics and Statistics, Old Dominion University.

Honorable Mention:

A Note on Latent Semantic Analysis as a Tool to Perform Correspondence Analysis. Jayesh Srivastava, Department of Mathematics and Statistics, Old Dominion University. 